\title{
A label-free Electrochemical Immunosensor for Anti-Mullerian Hormone Detection on Graphene-Au Nanocomposite
}

\author{
Lingling Li, Yongling Yu, Ping Chen and Weixia Liu* \\ The First Affiliated Hospital of Henan University of Traditional Chinese Medicine, Zhengzhou, \\ 450000, China \\ *E-mail: liuweixia68@aliyun.com
}

doi: $10.20964 / 2017.08 .40$

Received: 23 April 2017 / Accepted: 2 June 2017 / Published: 12 July 2017

\begin{abstract}
This study reported the construction of a graphene sensor based on poly(3,4ethylenedioxythiophene)/Au nanoparticles, abbreviated as AuNPs/PEDOT/GR. The fabrication process consisted of two steps. First, the synthesis of PEDOT nanorods grown on graphene oxide nanosheets (PEDOT/GO) was conducted via liquid-liquid interfacial polymerization. Then, HAuCl4 was chemically reduced by $\mathrm{NaBH} 4$. The determination of anti-Mullerian hormone (AMH) was realized using a sensitive and facile AuNPs/PEDOT/GR-based immunosensor by measuring the electrochemical response variation before and after the immunoreaction.
\end{abstract}

Keywords: Anti-mullerian hormone; Poly(3,4-ethylenedioxythiophene); Electrochemical immunoassay; Graphene; Au nanoparticles

\section{$\underline{\text { FULL TEXT }}$}

(C) 2017 The Authors. Published by ESG (www.electrochemsci.org ). This article is an open access article distributed under the terms and conditions of the Creative Commons Attribution license (http://creativecommons.org/licenses/by/4.0/). 